\title{
Motion - Laparoscopic Nissen fundoplication is more cost effective than oral PPI administration: Arguments for the motion
}

\author{
Lee L Swanström MD
}

\begin{abstract}
LL Swanström. Motion - Laparoscopic Nissen fundoplication is more cost effective than oral PPI administration: Arguments for the motion. Can J Gastroenterol 2002;16(9):621-623.
\end{abstract}

Gastroesophageal reflux disease is a mechanical disorder of the foregut. While medications can only provide symptom relief, surgery can correct the pathophysiological abnormality of the lower esophageal sphincter. The costs of medical and surgical therapy are much greater than the costs of medication or hospitalization alone. In the case of medical therapy, one must consider the costs of serial monitoring and of failed treatment. The effectiveness of treatment also depends on patient-related factors, including weight, socioeconomic factors, smoking, alcohol use, dietary habits and the use of nonsteroidal anti-inflammatory drugs. Surgical results depend on the experience and skill of the surgeon, as well as the attributes of the institution in which the procedure is undertaken. Therefore, studies that come from specialized centres may not be applicable to the community. Data from the author's facility indicate that laparoscopic Nissen fundoplication is the most cost effective option when it is undertaken by experienced surgeons on otherwise healthy patients who have documented gastroesophageal reflux disease.

Key Words: Gastroesophageal reflux disease; Laparoscopy; Nissen fundoplication; Proton pump inhibitors

\section{Proposition - La fundoplication \\ laparoscopique de Nissen présente un meilleur rapport coût-efficacité que les IPP oraux : Arguments en faveur de la proposition}

RÉSUMÉ : Le reflux gastro-œesophagien est un trouble de nature mécanique affectant le tractus digestif supérieur. Si les médicaments offrent un soulagement des symptômes seulement, la chirurgie peut pour sa part corriger l'anomalie pathophysiologique du sphincter œsophagien inférieur. Le coût du traitement médical et chirurgical est beaucoup plus élevé que celui des médicaments ou de l'hospitalisation seuls. Dans le cas du traitement médical, il faut tenir compte du coût des tests en série et de l'échec thérapeutique. L'efficacité du traitement dépend en outre de facteurs liés aux patients, notamment le poids, certains facteurs socioéconomiques, le tabagisme, la consommation d'alcool, les habitudes alimentaires et l'utilisation d'anti-inflammatoires non stéroïdiens. Les résultats de la chirurgie dépendent, quant à eux, de l'expérience et de l'habileté du chirurgien, de même que de certaines caractéristiques propres à l'établissement où l'intervention se déroule, les études provenant de centres spécialisés risquant de ne pas pouvoir s'appliquer à la communauté. Les données fournies par l'établissement de l'auteur indiquent que la fundoplication laparoscopique de Nissen est l'option la plus économique lorsqu'elle est pratiquée par des chirurgiens d'expérience sur des patients par ailleurs en bonne santé qui souffrent de reflux gastro-œsophagien documenté.

This article was originally presented at a symposium entitled, "Controversies in Gastroenterology", sponsored by Axcan Pharma, Toronto, Ontario, April 8-10, 2002

Department of Minimally Invasive Surgery, Legacy Health System, Portland, Oregon, USA

Correspondence and reprints: Dr Lee L Swanström, Department of Minimally Invasive Surgery, Legacy Health System, 501 North Graham Street, Suite 120, Portland Oregon 97227, USA. Telephone 503-288-6167, fax 503-288-3437, e-mail lswanstr@lhs.org 


\section{"A chance to cut is a chance to cure ..." Anonymous (surgeon)}

G astroesophageal reflux disease (GERD) can have a tremendous impact on the patient's quality of life. It can disrupt sleep, dietary patterns and workplace productivity, and can require daily use of medication (1). In addition, GERD is a risk factor for peptic esophageal stricture, chronic gastrointestinal blood loss and esophageal adenocarcinoma.

Reflux disease is a mechanical foregut disorder. The most common pathophysiological abnormalities are incompetence or inappropriate relaxation of the lower esophageal sphincter. These abnormalities can be accompanied by defective esophageal clearance, delayed gastric emptying and/or gastric acid hypersecretion. While medical treatments provide symptom relief, the aim of surgery is to correct the underlying physiological defect (2). The choice between medical and surgical treatment is determined by the patient, but can be influenced by the physician's recommendation. The physician's opinion should be based on outcomes data, practice guidelines or algorithms, or informed patient preference. It is often affected, however, by personal bias according to training or anecdotal experience.

The analysis of cost effectiveness is a relatively new branch of outcomes research, based on the need to rationally allocate finite medical resources. The process of deter-

\section{TABLE 1}

\section{Costs associated with medical therapy}

The costs of the medication itself

The costs of initial diagnostic tests

The costs of follow-up examinations, including endoscopy and histological assessment of biopsy specimens

\section{Professional fees}

The costs of repeated visits to the doctor's office, clinic or emergency department

The costs of treatment of complications due to medical failure, such as bleeding, aspiration or peptic stricture

The costs of surgical treatment of giant paraesophageal hernias and other entities that result from the natural progression of the disease

\section{TABLE 2}

\section{Costs associated with surgical therapy}

The costs of the hospital stay

The costs of surgical facilities and equipment

The costs of preoperative evaluation, including endoscopy, esophageal manometry, $24 \mathrm{~h} \mathrm{pH}$ monitoring, laboratory tests, electrocardiogram and other tests

Professional fees

The costs of medical or repeat surgical treatment of complications of the disease or of failed surgical therapy, including bleeding, infection, stricture or recurrent reflux symptoms mining the cost effectiveness of diverse therapies can be quite complex. It is probably not sufficient to compare annual expenditures on medication with the hospital charges related to surgery. The true costs of medical and surgical treatments are listed in Tables 1 and 2 .

The major determinants of costs are the success and complication rates. If both medical and surgical treatment were assumed to be $100 \%$ successful at either preventing reflux or controlling symptoms, then surgery would be the logical choice, at least for patients with an expected lifespan of at least five years (Figure 1). Such a comparison is misleading, however, because it is based on optimal treatment outcomes. The actual outcomes of medical therapy include:

- successful treatment with the initial medication dose;

- requirement for large or escalating doses of medication, such as proton pump inhibitors;

- requirement for the addition of other medications, such as prokinetics;

- crossover to surgical treatment because of dissatisfaction with medical management;

- development of complications of GERD, despite adequate symptom control; and

- the requirement for serial endoscopy because of the occurrence of Barrett's epithelium, dysphagia or bleeding.

The likelihood of each of these outcomes depends on the details of treatment and certain demographic features (eg, weight, geographic setting and socioeconomic status) and habits (eg, smoking, alcohol use, dietary habits and use of nonsteroidal anti-inflammatory drugs).

Likewise, surgical results depend on many factors, including institutional experience, resources and quality of care, and the skill and experience of the surgeon (3). As with medical therapy, patient-related factors are also important. The peer-reviewed surgical literature is widely analyzed and quoted, but can be criticized because it is often derived from high-volume specialized centres, and might

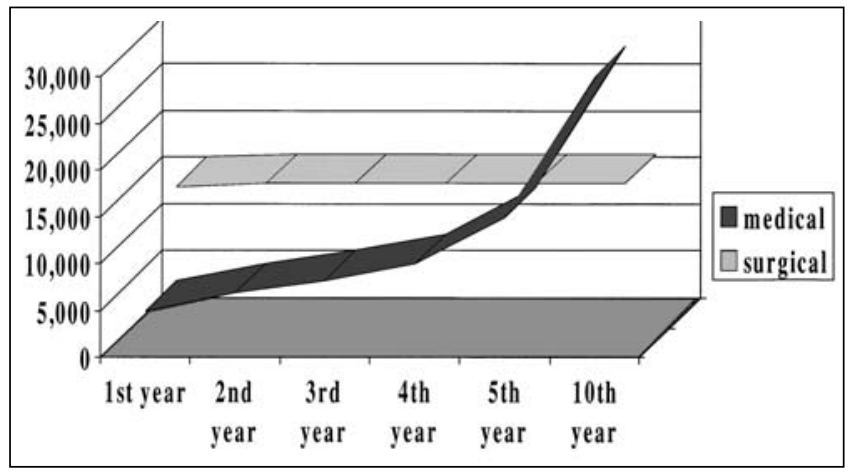

Figure 1) Cumulative costs of surgery versus medical treatment for chronic gastroesophageal reflux disease 


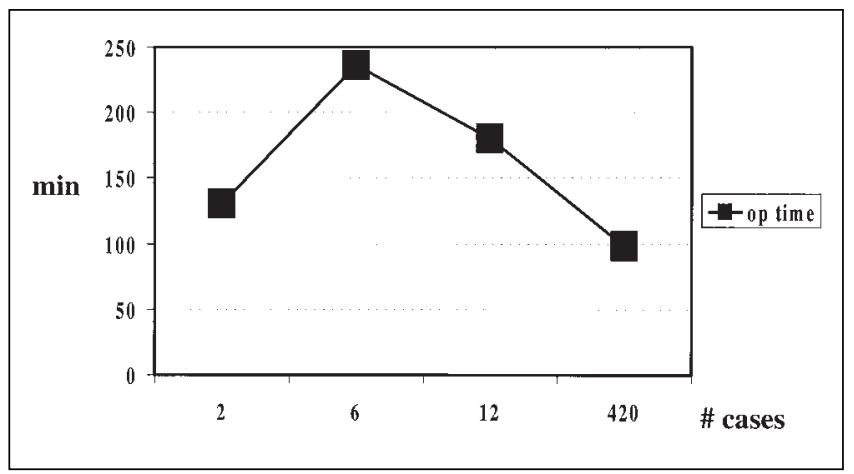

Figure 2) Relation of volume to operating time, antireflux surgery 1998 to 2000

not reflect the results that can be achieved by community surgeons. We have documented this 'learning curve' effect by prospectively gathering outcomes data for all surgeons doing antireflux surgery (Figures 2, 3).

Because the costs and fees related to treatment vary from place to place, it is probably appropriate for each institution to track their own outcomes and to analyze cost information based on actual costs, patient charges and reimbursements $(4,5)$. Finally, medical and surgical treatment should be compared in terms of the patient's quality of life. This can influence the long term costs of interventions, especially in terms of workplace productivity and even the susceptibility to other diseases. It is obviously difficult to assign a monetary value to these parameters, and this type of analysis has not been done for GERD. Nevertheless, surgical treatment has been shown to provide a quality of life superior to that of chronic medical therapy (6-8).

Data from our institution have shown that laparoscopic surgery is the most cost effective strategy when the following conditions are met:

- the patient has documented GERD (ie, a DeMeester score higher than 20 at $24 \mathrm{~h} \mathrm{pH}$ monitoring);

- the patient has an American Association of Anesthesia grade III or less and can be expected to live more than three years; and

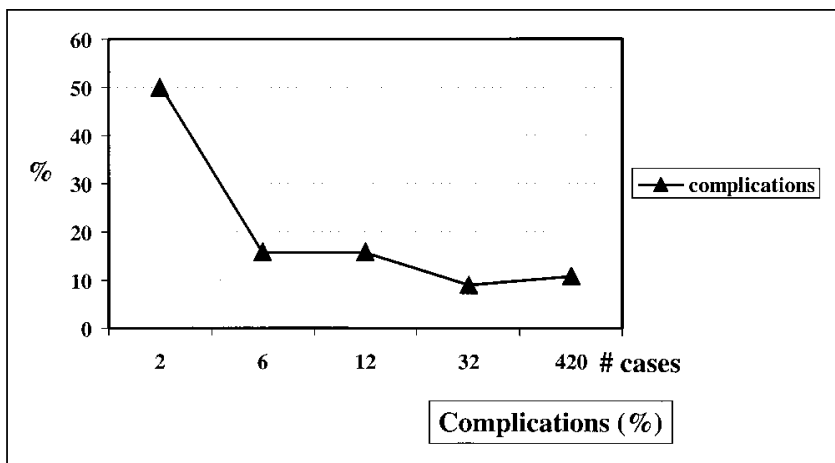

Figure 3) Relation of volume to complication rates, antireflux surgery 1998 to 2000

- the surgeon performs more than 25 laparoscopic fundoplications per year.

For such patients, a chance to cut (laparoscopically) is a chance to cure.

\section{REFERENCES}

1. Bloomston M, Zervos E, Gonzalez R, Albrink M, Rosemurgy A. Quality of life and antireflux medication use following laparoscopic Nissen fundoplication. Am Surg 1998;64:509-13.

2. Hunter JG, Trus TL, Branum GD, Waring JP, Wood WC. A physiologic approach to laparoscopic fundoplication for gastroesophageal reflux disease. Ann Surg 1996;223:673-85.

3. Peters JH, DeMeester TR. Indications, principles of procedure, selection and techniques of laparoscopic Nissen fundoplication. Semin Lap Surg 1995;2:27-44.

4. Van den Boom G, Go PMMYH, Hameeteman W, Dallemagne B, Ament AJHA. Cost effectiveness of medical versus surgical treatment in patients with severe or refractory gastroesophageal reflux disease in the Netherlands. Scand J Gastroenterol 1996;31:1-9.

5. Kahrilas PJ. Management of GERD: medical versus surgical. Semin Gastrointest Dis 2001;12:3-15.

6. Nessen SC, Holcomb J, Tonkinson B, Hetz SP, Schreiber MA. Early laparoscopic Nissen fundoplication for recurrent reflux esophagitis: a cost-effective alternative to omeprazole. J Soc Laparosc Surg 1999;3:103-6.

7. Eypasch E, Thiel B, Sauerland S. Laparoscopic fundoplication for gastro-oesophageal reflux disease - a consensus development conference and the evidence-based benefit. Langenbachs Arch Surg 2000;385:57-63.

8. Cuschieri A, Hunter J, Wolfe B, Swanstrom LL, Hutson W. Multicenter prospective evaluation of laparoscopic antireflux surgery. Preliminary report. Surg Endosc 1993;7:505-10. 


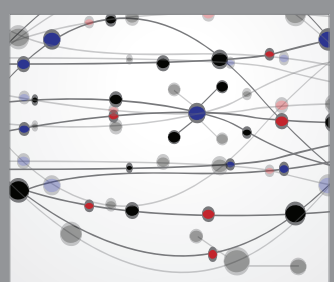

The Scientific World Journal
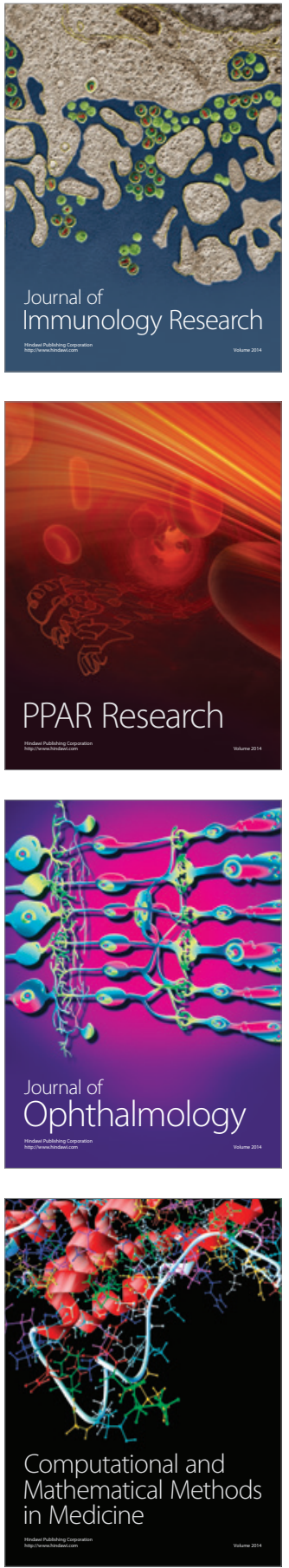

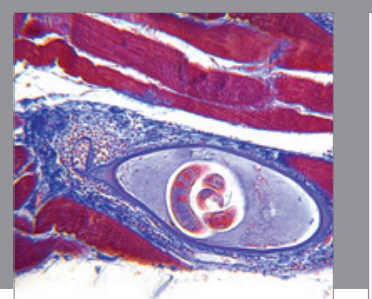

Gastroenterology Research and Practice

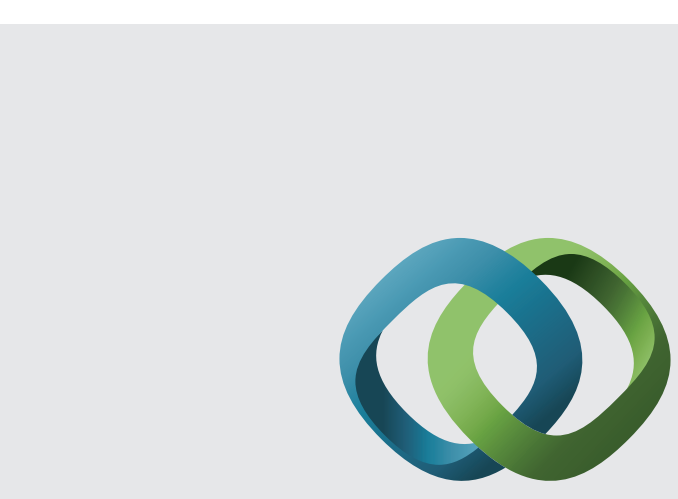

\section{Hindawi}

Submit your manuscripts at

http://www.hindawi.com
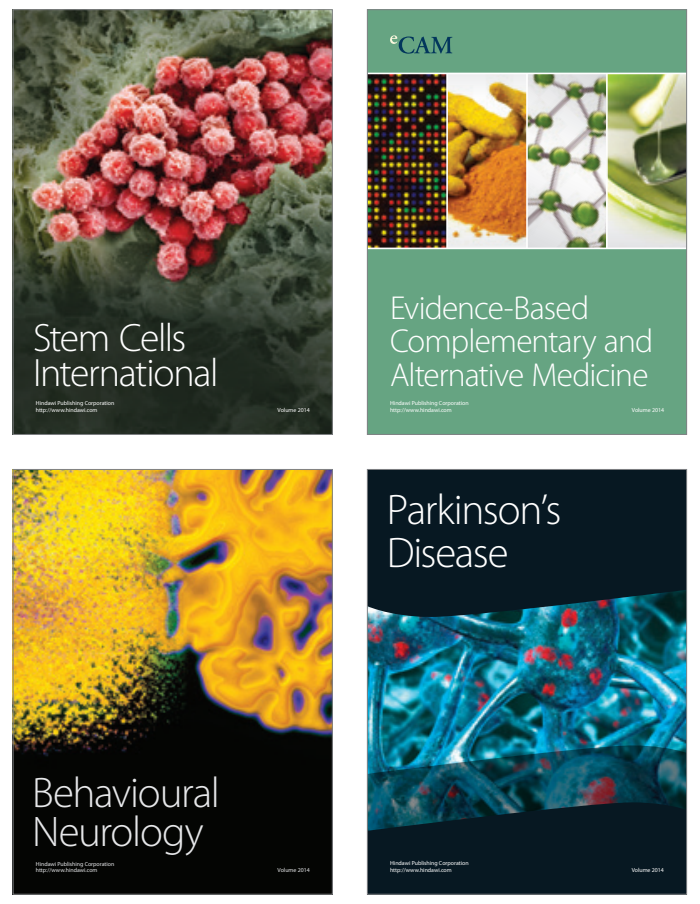
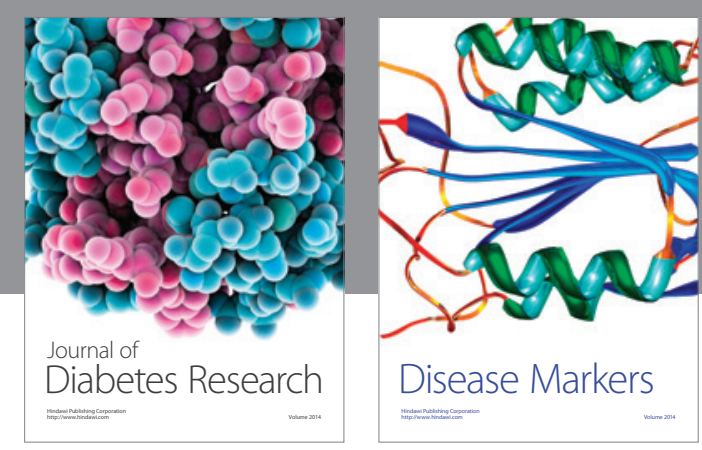

Disease Markers
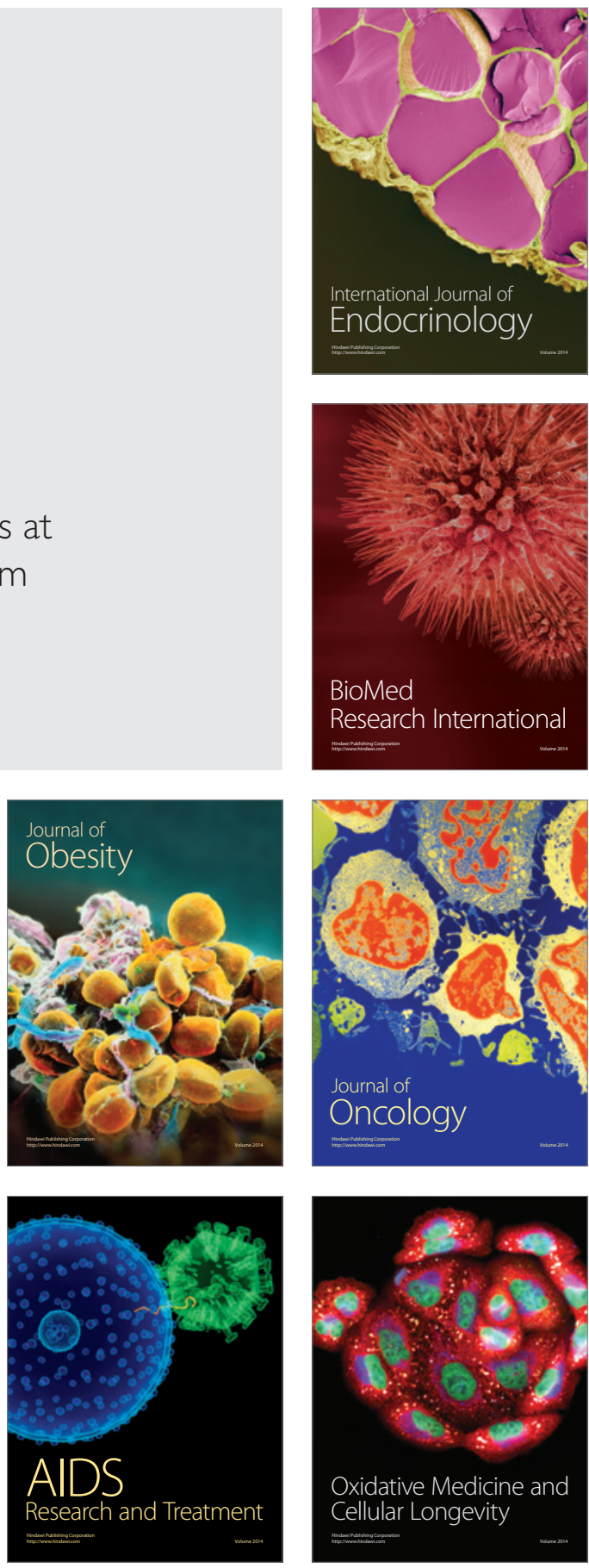